\title{
Aplicação da tecnologia do vácuo no desenvolvimento de um sistema de coleta de vapores orgânicos para análise ambiental
}

\section{Application of vacuum technology in the development of an organic vapour collection system for environmental analysis}

Ligia Miyuki Nagao Asano ${ }^{1}$, Silvia Pierre Irazusta ${ }^{1}$, Elisabeth Pelosi Teixeira ${ }^{1 *}$, Francisco Tadeu Degasperi ${ }^{2}$

\section{RESUMO}

A poluição atmosférica causa diversos incômodos, não sendo restrita a poluentes visíveis na atmosfera urbana, mas também em ambientes ocupacionais. O objetivo deste trabalho foi apresentar o estudo matemático de um arranjo experimental usando a tecnologia do vácuo para obtenção de amostra de ar indoor, visando a detecção de compostos orgânicos voláteis (COVs) em uma estação de tratamento de resíduos de serviços de saúde (RSS). O método foi baseado em cálculos matemáticos para captar o fluxo de gases emitidos pelo equipamento de esterilização (autoclave), usando um sistema de vácuo, visando aprisionar os vapores orgânicos por condensação a baixas temperaturas $\left(\mathrm{CO}_{2}\right.$ sólido), de modo a obter concentração suficiente para detecção em espectrômetro de massa. Os resultados apresentam os cálculos matemáticos e um sistema de vácuo sustentado por dois componentes: a bomba de vácuo e a armadilha gelada. O propósito da coleta dos vapores foi sua identificação, usando métodos analíticos disponíveis e confiáveis, como o analisador de gases residuais (RGA). O trabalho concluiu que é possível construir armadilhas de vapor de autoclaves de forma simples e econômica, operadas na estação de tratamento de RSS, possibilitando a análise e identificação dos componentes do vapor gerado e contribuindo para melhorar a qualidade do ar indoor.

Palavras-chave: Sistema de vácuo, Poluição indoor, Armadilha gelada.

\begin{abstract}
Air pollution causes many annoyances, not being restricted to pollutants visible in the urban atmosphere, but also in occupational environments. The objective of this work was to present the mathematical study of an experimental arrangement, using vacuum technology to obtain indoor air samples, aiming at the detection of volatile organic compounds (COVs) in a health service waste treatment plant. The method was based on mathematical calculations to capture the flow of gases emitted by the autoclave equipment using a vacuum system to trap organic vapors by condensation at low temperatures (solid $\mathrm{CO}_{2}$ ) in order to obtain sufficient concentration for mass spectrometer detection. The results present the mathematical calculations and a vacuum system supported by two components: the vacuum pump and the frozen trap. The purpose of the vapor collection was its identification, using available and reliable analytical methods, and the waste gas analyzer (RGA) was chosen. The work concluded that it is possible to construct simple and economical autoclave steam traps, operated in the RSS treatment plant, allowing the analysis and identification of the steam components generated and contributing to improve indoor air quality.
\end{abstract}

Keywords:Vacuum system, Indoor pollution, Icy trap.

${ }^{1}$ Centro Estadual de Educação Tecnológica Paula Souza - Faculdade de Tecnologia de Sorocaba José Crespo Gonzáles - Sorocaba (SP) - Brasil. ${ }^{2}$ Centro Estadual de Educação Tecnológica Paula Souza - Faculdade de Tecnologia de São Paulo - São Paulo (SP) - Brasil Autor correspondente: elisabeth.teixeira@fatec.sp.gov.br

Recebido: 30 Jul. 2019 Aprovado: 21 Ago. 2019 


\section{INTRODUÇÃO}

O interesse por estudos sobre a Qualidade de Ar Interior (QAI) surgiu após a descoberta de que a diminuição das taxas de troca de ar nesses ambientes era a grande responsável pelo aumento da concentração de poluentes biológicos e não biológicos no ar interno. Essa preocupação se justifica uma vez que a maioria das pessoas (em torno de 80 a 90\%) passa a maior parte do seu tempo dentro de edifícios e, consequentemente, exposta aos seus poluentes ${ }^{1,2,3}$.

Compostos orgânicos, em especial os voláteis (COV), constituem um sério problema ambiental e social ${ }^{4,5}$. COVs podem ser produzidos por inúmeras fontes industriais e de prestadores de serviço, além da ocorrência por emissões indiretas, inclusive naturais, como por processo de decomposição. Esses compostos, por sua vez, podem influir na saúde humana, criando desde sintomas aparentemente inócuos ou de pouca importância, como tosse, rinite e alergia, até a síndrome dos edifícios doentes $^{6}$, cujas emissões severas podem levar a quadros clínicos mais agudos. Entre as atividades industriais que geram COVs, estão a indústria metalúrgica e química, e entre os serviços, os de lavanderia e sapataria, pela evaporação de solventes ${ }^{7,8}$.

Neste trabalho, são descritos o desenvolvimento e a construção de um sistema a vácuo para retenção de COVs. Os métodos mais frequentes para proceder à amostragem desses compostos são borbulhamento em solvente, concentração criogênica, adsorção em um sólido ou ainda a colheita em canisters. Estes últimos são recipientes com geometria aproximadamente cilíndrica, de aço ou alumínio passivado, que podem ou não ser pressurizados para aumentar o volume de amostra colhida9.

A retenção dos vapores neste estudo está baseada no aprisionamento molecular realizado por meio de uma superfície criogênica. O pré-tratamento das amostras para preservar suas características e diminuir o limite de detecção é comum na área de COVs, especialmente indoor, devido à baixa concentração do contaminante e a pequena massa de amostra. $\mathrm{O}$ aprisionamento das moléculas promove o aumento de sua concentração, facilitando a identificação e a quantificação por meio de um analisador de gases residuais.

$\mathrm{O}$ arranjo experimental desenvolvido pode ser utilizado em ambientes laborais que necessitem de indicação rápida da presença de compostos tóxicos. O sistema não ocupa muito espaço e nem precisa de mão de obra altamente especializada para sua operação, podendo operar quase que continuamente monitorando o ambiente indoor.

O objetivo deste trabalho foi elaborar didaticamente o estudo matemático para o desenvolvimento de um arranjo experimental simples, usando a tecnologia do vácuo para obtenção de amostra de ar indoor, visando a detecção de COVs no ambiente ocupacional de uma estação de tratamento de resíduos de serviços de saúde (RSS), que utiliza calor úmido sob pressão para a descontaminação dos resíduos infectantes ${ }^{10}$.

\section{Fundamentação teórica}

Segundo Belli Filho e Lisboa ${ }^{11}$, odor é uma mistura de moléculas voláteis, de origem orgânica ou mineral, com propriedades físicoquímicas distintas que afetam sensorialmente a mucosa nasal. O DNA humano possui 1 gene responsável pela audição, 3 pela visão, 12 pelo paladar e 1.000 pelo olfato, sendo que as 50 milhões de células receptoras que existem na cavidade nasal são capazes de detectar mais de 10.000 odores encontrados na natureza ${ }^{12}$.

A capacidade olfativa das pessoas é bastante variável e por isso a informação acerca do limiar de odor é dada para uma faixa de concentração do menor valor (para as pessoas mais sensíveis) até o maior valor e para a média geométrica da população testada (média geométrica é uma medida de tendência central calculada multiplicando-se todos os valores $\mathrm{n}$ e extraindo-se a raiz de índice n deste produto $)^{13}$.

Não é incomum que odores, principalmente por "emissões crônicas", sejam percebidos ou detectados em baixo ou muito baixo limite de detecção. A análise de intensidade do odor pode ser feita tanto através de método de escala dinâmica quanto através do método de escala estática. No método dinâmico, um odorante padrão, normalmente o butanol, é apresentado aos jurados através de um olfatômetro. Nesse método, o odor sentido é comparado ao odor padrão apresentado de forma subjetiva (exemplo: este odor é duas vezes mais forte que o odor padrão) e com os resultados obtidos são relacionados a uma escala subjetiva (exemplo: fraca - moderada - forte). No método estático, várias amostras de odor padrão, normalmente o butanol, com concentrações prédefinidas, são apresentadas aos jurados em recipientes. Os jurados devem então comparar a amostra do odorante com a intensidade do odor padrão contido nos frascos. Cada concentração é relacionada a uma escala subjetiva de intensidade (exemplo: fraca - moderada - forte) $)^{12}$.

A análise da intensidade pode ser feita através do método do butanol, que tem uma escala de referência, com concentrações padronizadas a serem diluídas em água ou ar puro. As diluições recomendadas são dadas pela Associação Francesa de Normalização (AFNOR, do francês Association Française de Normalisation $)^{14}$.

O odor ainda pode ser identificado de acordo com a escala de categoria de odor da VDI 38882 Parte 11992 (determinação da intensidade do odor). A escala está apresentada na Tabela $1^{14}$.

Tabela 1: Escala de categoria de odor.

\begin{tabular}{|c|c|}
\hline Odor & Nível de Intensidade \\
\hline Extremamente forte & 6 \\
\hline Muito forte & 5 \\
\hline Forte & 4 \\
Distinto & 3 \\
Fraco & 2 \\
Muito fraco & 1 \\
Não perceptível & 0 \\
\hline
\end{tabular}


A intensidade é dada em função da concentração do odorante no ar e é representada pela lei de Stevens, mostrada pela Eq. 1 e representada na Fig. $1^{14}$.

$$
\log I=b \log C+\log a
$$

Sendo: a, constante de Stevens, b, traduz o crescimento da intensidade odorante em função da constante (entre 0,2 e 0,8), I, intensidade e C: concentração do odorante



Figura 1: Variação da intensidade odorante de um corpo puro em função da concentração.

A detecção e mensuração de compostos com o intuito de impedir ou diminuir o incômodo provocado pela percepção do odor exigem equipamentos sofisticados e de alto custo, bem como mão de obra especializada para a sua operação. Apesar disso, existem no mercado sensores que detectam classes de compostos, sem qualquer preocupação com a definição de deteç̧ão da composição específica de uma amostra particular, avaliando, em essência, o total de emissão. Esses sensores são baratos, porém com um alcance bastante limitado.

\section{MATERIAIS E MÉTODOS}

Neste trabalho, foi desenvolvido um concentrador de amostra de vapores usando equipamentos baseados na tecnologia do vácuo, tendo o analisador de gases residuais (RGA, do inglês residual gas analyzer) como equipamento principal, o qual também utiliza bombas de alto vácuo para o seu funcionamento.

O vapor gerado pelo equipamento de esterilização utilizado pela empresa de tratamento de RSS foi coletado por meio de uma armadilha gelada, sendo seu transporte realizado por meio de um sistema de vácuo. O sistema de vácuo opera à pressão atmosférica, tendo como equipamento principal uma bomba de vácuo mecânica de palhetas.

No desenvolvimento deste artigo, será apresentado o circuito de vácuo completo, com discussão da necessidade de cada componente, além dos cálculos necessários para se obter os volumes de gás e de vapor bombeados, em função da velocidade de bombeamento da bomba de vácuo e da pressão de trabalho.
Será apresentada também uma discussão sobre os cuidados na operação e utilização do sistema de vácuo, caracterizando suas limitações.

\section{Método de aprisionamento dos vapores orgânicos}

A coleta de vapores orgânicos para sua posterior análise está baseada no transporte de gases e vapores com uso da tecnologia do vácuo. A coleta consistiu no aprisionamento destes vapores por meio de uma superfície gelada, de modo que ocorreu uma diminuição significativa da pressão de vapor dos condensados que estavam na forma de vapor. Os gases presentes no circuito de bombeamento do sistema de vácuo não são aprisionados devido ao fato de suas temperaturas críticas serem muito abaixo da temperatura da superfície criogênica. O princípio geral do processo de coleta dos vapores é o seguinte: uma das extremidades de um tubo é conectada ao ponto de coleta do local de descarga do material líquido ou gasoso do equipamento de esterilização (autoclave) da planta de tratamento de RSS; a outra extremidade do tubo de coleta é conectada à entrada da armadilha gelada; e a outra extremidade da armadilha gelada é conectada à bomba de vácuo mecânica de palhetas. A linha do bombeamento de gases e vapores descrita sucintamente acima não apresentou os componentes auxiliares existentes de fato no circuito de vácuo.

A Fig. 2 apresenta a linha de bombeamento de gases e vapores, mostrando o essencial para o seu funcionamento e ainda a posição da definição das grandezas básicas para o cálculo da taxa de transferência (throughput) de gases.

Por meio do conhecimento da curva de velocidade de bombeamento da bomba mecânica de vácuo e da condutância da linha de bombeamento foi determinada a velocidade efetiva de bombeamento.

A bomba de vácuo utilizada é do tipo mecânica de palhetas de duplo estágio com velocidade de bombeamento igual a $S_{B M}=0,7 \mathrm{~L} \cdot \mathrm{s}^{-1}$. As informações sobre a bomba de vácuo são obtidas por meio do catálogo da empresa Oerlikon-Leybold. A bomba de vácuo é de denominação TRIVAC E, selada a óleo (ou de palhetas rotativas). A curva da velocidade de bombeamento em função da pressão da bomba de vácuo TRIVAC E é mostrada na Fig. 3.

O tubo utilizado para realizar o bombeamento dos gases e vapores no tanque de rejeitos tem diâmetro interno de 4,2 $\mathrm{mm}$ e comprimento de $5 \mathrm{~m}$. A pressão na entrada do tubo no tanque de rejeitos é a mesma da pressão atmosférica. Foi adotada a pressão atmosférica local de $\mathrm{p}_{\text {atm }}=940 \mathrm{mbar}$. A Figura 4 mostra o esquema do circuito de vácuo usado para fazer a coleta da amostra dos vapores com origem no tanque de rejeitos da autoclave, onde também estão indicados todos os componentes auxiliares usados do sistema coletor de vapor a vácuo.

Foi considerado que as válvulas e o fole sensível (do mesmo material do tubo da linha de bombeamento) têm o mesmo diâmetro do tubo da linha de bombeamento. Além disso, foi considerado que as condutâncias tanto da armadilha gelada 


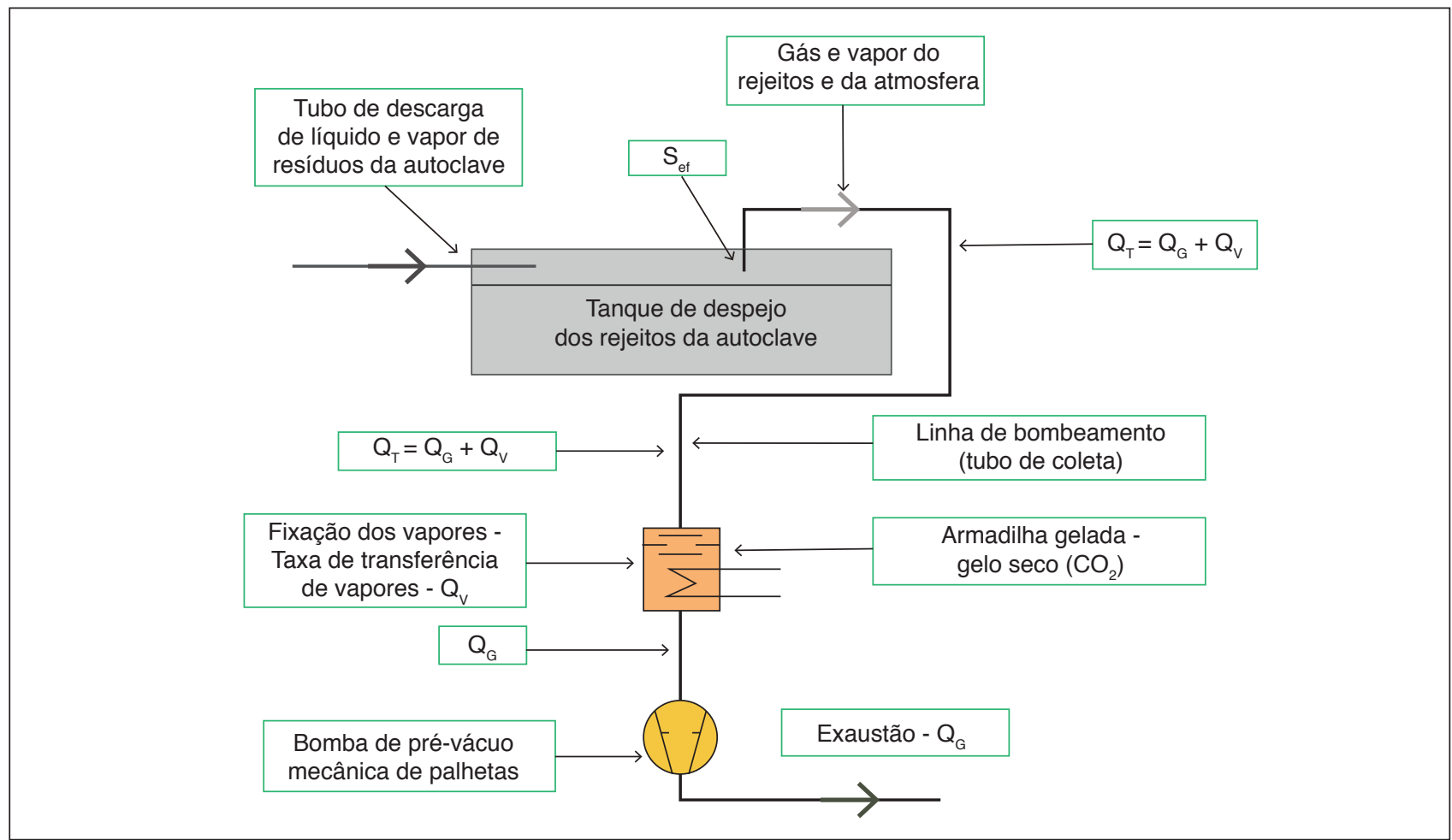

Figura 2: Linha de bombeamento dos gases e vapores devido à ação da bomba de vácuo.

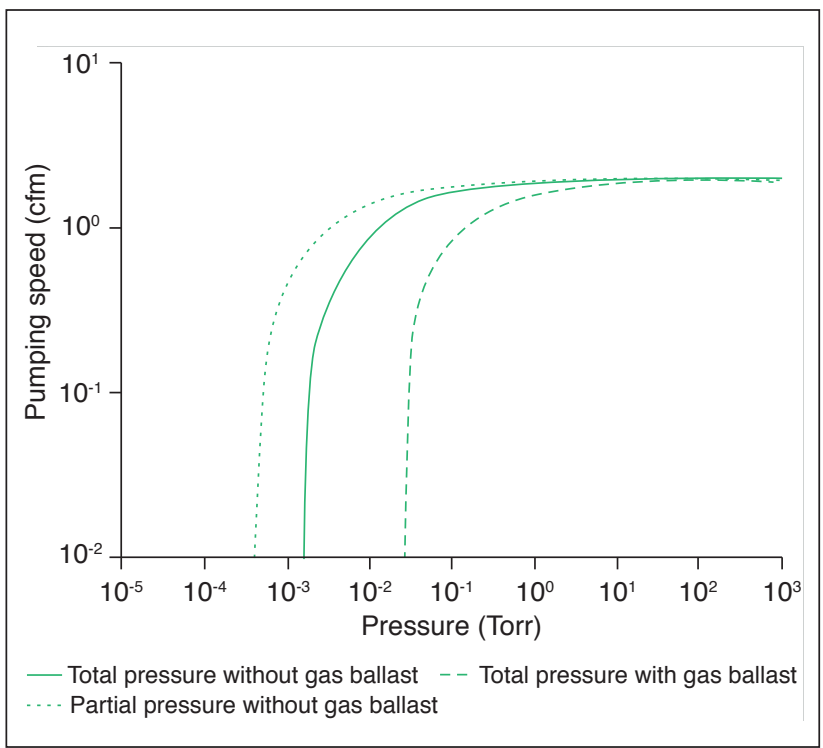

Figura 3: Curva da velocidade de bombeamento em função da pressão da bomba de vácuo TRIVAC E de $35 \mathrm{~L}$. $\mathrm{min}^{-1}$. O eixo vertical (velocidade de bombeamento) do gráfico deve ser multiplicado por 0,14 para obter a velocidade de bombeamento da bomba de vácuo em litros por segundo $\left(\text { L.S } \text { S }^{-1}\right)^{15}$.

como do filtro da bomba mecânica são muito maiores que as condutâncias do tubo e das válvulas da linha de bombeamento. A justificativa dessa simplificação está no fato de as dimensões das seções da armadilha gelada e do filtro da bomba de vácuo serem muito maiores que a sessão do tubo da linha de bombeamento (de diâmetro de 4,2 mm).

Considera-se que o transporte de gases e vapores na pressão atmosférica, $\mathrm{p}_{\text {atm }}=940$ mbar, foi realizado no regime de

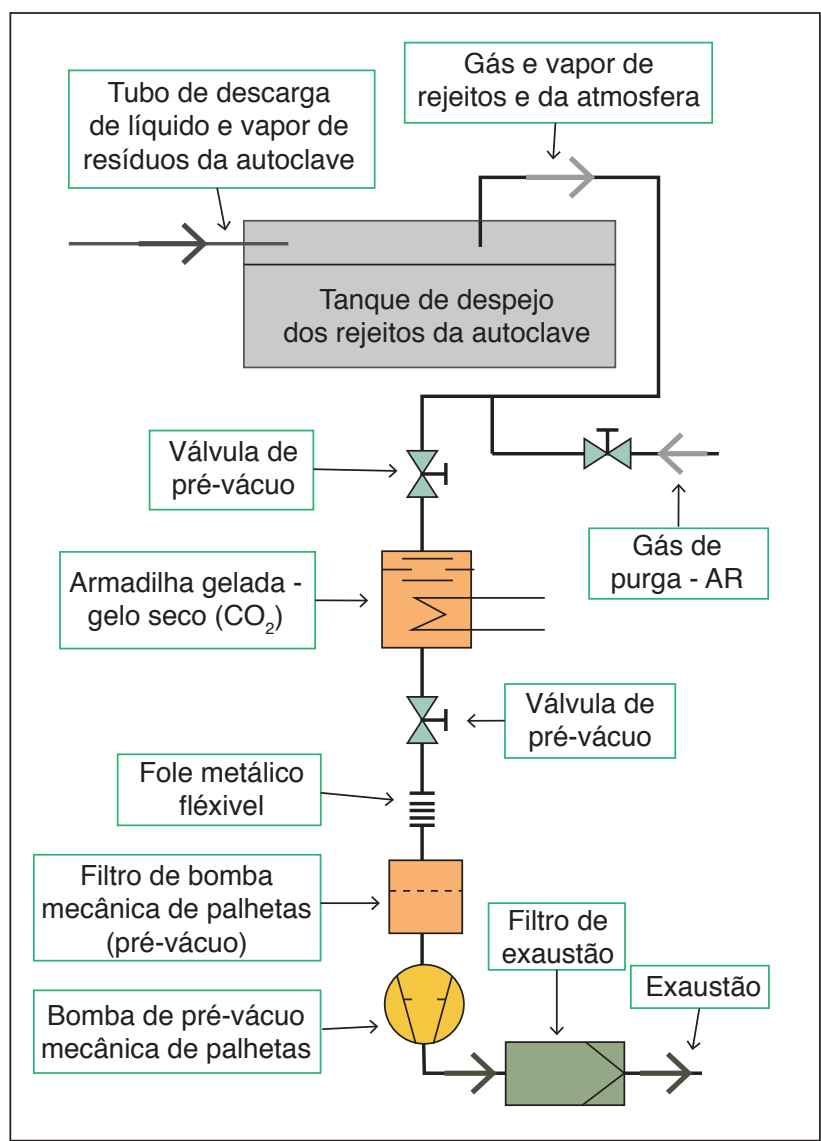

Figura 4: Esquema do percurso dos gases e vapores devido à ação da bomba de vácuo.

escoamento viscoso. Nesse caso, as condutâncias em geral são altas, como mostrado nos cálculos na Eq. 2 . 


$$
\left.C_{L B}=134 \times d^{4} / L \times P_{M}=134 \times d^{4} / L \times\left(P_{1}+P_{2}\right)\right) / 2
$$

Sendo: $d$, o diâmetro do tubo da linha de bombeamento $(\mathrm{cm})$; $L$, o comprimento do tubo da linha de bombeamento $(\mathrm{cm}) ; P_{M^{2}}$ a pressão média, medidas nas extremidades do tubo (mbar); $C_{L B}$, a condutância da linha de bombeamento.

A constante 134 incorpora o valor da viscosidade do gás bombeado, tendo sido adotado como a viscosidade do ar atmosférico. Essa aproximação deve-se ao fato de não serem conhecidos os vapores que participavam da mistura gasosa bombeada e nem a concentração de cada componente na mistura.

A pressão média pode ser adotada como sendo a pressão atmosférica, visto ser nessa pressão que o bombeamento dos vapores é realizado. Dessa forma, o valor da condutância do tubo para a passagem do gás à pressão atmosférica tem valor mostrado na Eq. 3.

$$
C_{L B}=134 \times(0,42)^{4} / 500 \times 10^{3}=>C_{L B}=8,4 L \cdot \mathrm{s}^{-1}
$$

É observado que mesmo considerando um diâmetro pequeno e um comprimento grande de tubo, o valor da condutância no regime viscoso à pressão atmosférica não é pequeno. A velocidade de bombeamento da bomba de vácuo é de $S_{B M}=0,7 \mathrm{~L} \cdot \mathrm{s}^{-1}$. Temos que $C_{L B}>S_{B M}$ à pressão atmosférica. A determinação da velocidade efetiva de bombeamento pode ser alcançada como mostrado na Eq. 4.

$$
\begin{aligned}
\frac{1}{S_{e f}} & =\frac{1}{S_{B M}}+\frac{1}{C_{L B}}=>S_{e f}=\frac{S_{B M} \cdot C_{L B}}{S_{B M}+C_{L B}}= \\
& =\frac{0,7 \cdot 8,4}{0,7+8,4}=>S_{e f}=0,65 \text { L.S } S^{-1}
\end{aligned}
$$

O volume de vapor bombeado, em termos de taxa de transferência de gás (throughput), é dado pela Eq. 5a.

$$
\begin{aligned}
Q_{G T V} & =S_{e f} \cdot p_{a t m}=0,65 \cdot 10^{3}=> \\
& =>Q_{G T V}=650 \text { mbar. L. } s^{-1}
\end{aligned}
$$

O significado físico dessa grandeza pode ter a seguinte interpretação: o volume $S$ de vapor bombeado, quando o volume de $0,65 \mathrm{~L}$ e com pressão $10^{3}$ mbarentra pela extremidade do tubo da linha de bombeamento a cada segundo. Considerando-se a pressão atmosférica local de aproximadamente 920 mbar, a taxa de transferência de gás é igual a:

$$
\begin{aligned}
Q_{G+V} & =S_{e f} \cdot p_{S}=0,65 \cdot 920=> \\
& =>Q_{G+V}=580 \text { mbar. L. } s^{-1}
\end{aligned}
$$

Considerando-se que o valor da taxa de transferência de gás é composto por parte de gás da atmosfera local e parte dos vapores dos compostos orgânicos do rejeito do processo de tratamento dos resíduos, foi adotado o valor de $\mathrm{Q}_{G+V}=580 \mathrm{mbar} \cdot L \cdot \mathrm{s}^{-1}$ pelo fato da cidade de Sorocaba-SP (onde o experimento foi realizado) apresentar a pressão atmosférica próxima de 940 mbar. Assim, ao efetuar o bombeamento de gases e vapores, estes foram aprisionados pela armadilha gelada e aqueles foram bombeados pela bomba mecânica de palhetas e exauridos à pressão atmosférica.

A quantidade de massa ou número de moles bombeados pode ser alcançada por meio da definição de taxa de transferência de gás (throughput) dada pela Eq. 6:

$$
Q=\frac{d}{d t}(p \cdot v)=\frac{d n}{d t}(n R T)
$$

Considerando que o bombeamento se dê em pressão $p$ constante, e também a temperatura $T$ constante, ficamos com a Eq. 7:

$$
Q=p \frac{d v}{d t}=R T \frac{d n}{d t}
$$

Sendo: v o volume de gás e vapor (em L) bombeado a cada segundo.

Dessa forma, por meio da Eq. 6, foi determinado que $Q=R T \times(d n / d t)$, sendo $R$ a constante universal dos gases e $n$ o número de moles. Como encontramos que $\mathrm{Q}=580 \mathrm{mbar} \cdot L \cdot \mathrm{s}^{-1}$, temos na Eq. 8 que:

$$
\frac{d n}{d t}=\frac{Q}{R T}=\frac{580}{82,06 \cdot 298}=2,4 \cdot 10^{-2} \text { moles. } s^{-1}
$$

Assumindo a temperatura média local de $298 \mathrm{~K}$ (ou $25^{\circ} \mathrm{C}$ ), temos que o número de moles bombeados por segundo é $2,4 \cdot 10^{-2}$ moles $\cdot \mathrm{s}^{-1}$, adotando $R=82,06 \mathrm{mbar} \cdot \mathrm{L} \cdot \mathrm{mol}^{-1} \cdot \mathrm{K}^{-1}$.

Mesmo de posse do número de moles bombeados por segundo, não é possível determinar a quantidade de massa bombeada no período, devido ao fato de não se conhecer a composição da mistura gasosa bombeada. Essa quantidade está diretamente ligada à quantidade de vapor aprisionada na armadilha gelada. Portanto, essa grandeza pode ser considerada uma estimativa da grandeza de vapor condensada na armadilha gelada e usada na análise dos gases residuais.

\section{Arranjo e operação experimental}

O sistema de vácuo usado para o bombeamento de gases e vapores é sustentado por dois componentes fundamentais: a bomba de vácuo e a armadilha gelada. A bomba de vácuo é muito usada em sistema de vapor em geral. A armadilha gelada pode ser construída de forma bastante simples. Os outros componentes utilizados no sistema de vácuo também são comuns. 
Na Fig. 5, são apresentados os componentes do sistema de vácuo numerados para sua identificação, com o propósito de descrever sua função no sistema de vácuo e de mostrar sua ação na sequência da operação. O descritivo do sistema de vácuo traça também algumas considerações sobre a possibilidade de alteração de um componente por outro, se for o caso. O esquema do circuito do sistema de vácuo com seus componentes identificados por números também é mostrado.

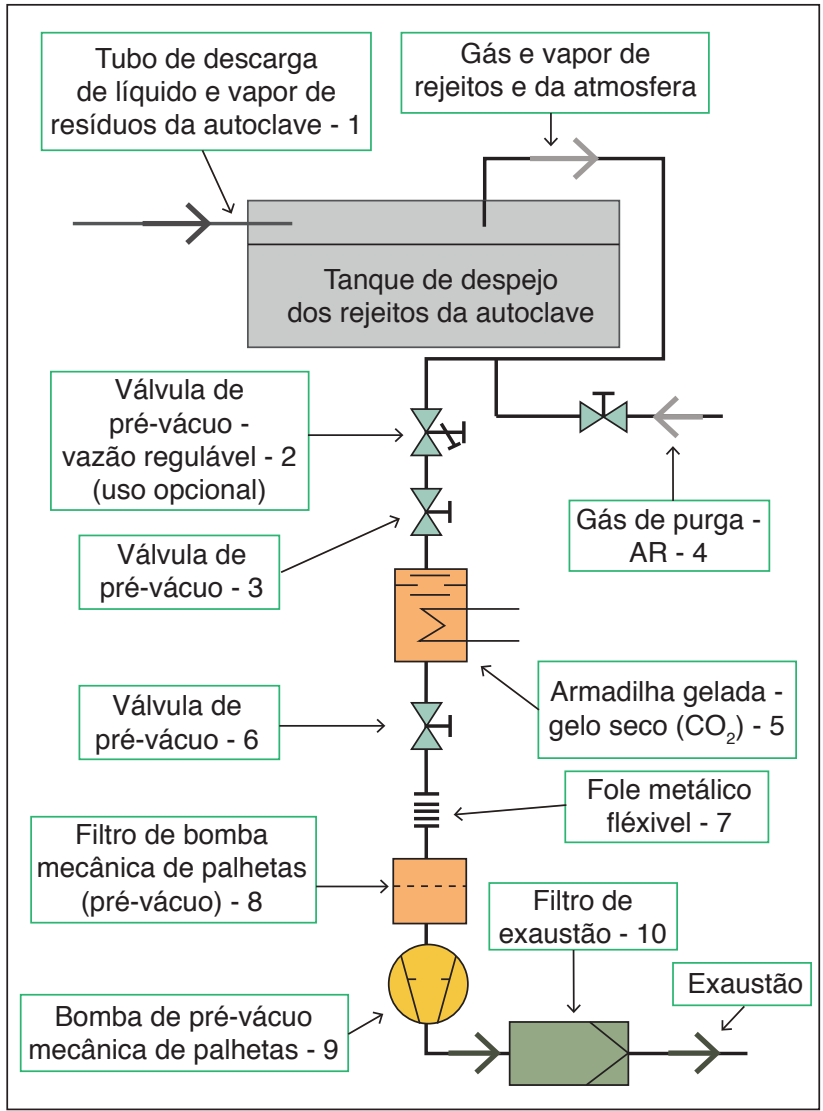

Figura 5: Esquema do circuito de vácuo com seus componentes identificados por números para sua descrição detalhada.

É possível ver o tanque de despejos dos rejeitos da autoclave (1), no qual a mistura líquida vinda da autoclave no final do ciclo de operação é armazenada. Em seguida, a válvula de prévácuo (2) tem sua vazão controlada; ela é opcional, e não foi usada neste estudo para fazer as capturas de vapor. A válvula (2) pode ser usada quando se deseja que a captura de vapor tenha a vazão diminuída. As válvulas de pré-vácuo (3) e (6) são usadas para isolar a armadilha gelada com os vapores aprisionados nela. Não foi necessária sua utilização nas capturas realizadas neste estudo. Essas válvulas são usadas para isolar a armadilha gelada com os vapores aprisionados nela. A válvula de gás de purga (4) é usada para limpar a linha de bombeamento com fluxo de ar da atmosfera e para remover possíveis materiais orgânicos na linha, que possam contaminar a atmosfera seguinte de vapor. A armadilha gelada (5) faz a retenção (aprisionamento) dos gases bombeados. Seu interior é formado por aletas para aumentar a área de aprisionamento de vapores. As aletas devem estar a baixa temperatura para que os vapores condensem em sua superfície. Há várias possibilidades tanto na forma da armadilha gelada como na maneira do resfriamento. No caso deste trabalho, foi usado gelo seco $\left(\mathrm{CO}_{2}\right.$ sólido) para criar a superfície gelada para a retenção dos vapores bombeados. É importante no projeto da armadilha gelada que os vapores tenham bastantes obstáculos gelados em sua passagem. O fole metálico sensível ou bellows (7) serve para tornar a linha de bombeamento flexível. Neste estudo, foi utilizado um tubo de plástico flexível para fazer a captação de vapores e gases. Em seguida, encontra-se o filtro da bomba de pré-vácuo (8), que deve ser usado para evitar, ou pelo menos diminuir, a quantidade de vapores que não foram aprisionados na armadilha gelada.

Cabe mencionar que a bomba de vácuo mecânica de palhetas (9) não pode operar por mais de 5 min em pressão atmosférica e que a velocidade de bombeamento de 1,5 a $2,5 \mathrm{~m}^{3} \cdot \mathrm{h}^{-1}$ foi suficiente para a tarefa de coleta de vapores. Neste trabalho, a duração de bombeamento não foi superior a $1 \mathrm{~min}$, visto que esse tipo de bomba de palheta não é projetado para operar por longos período à pressão atmosférica. Durante esse intervalo de tempo, o diâmetro do tubo da linha de bombeamento foi de $4,2 \mathrm{~mm}$; com isso, a vazão foi menor considerando o diâmetro de acesso da bomba mecânica de palhetas $(25 \mathrm{~mm})$. Finalmente, o filtro de exaustão (10) deve ser usado se o bombeamento for realizado em ambiente fechado. Dessa forma, impede-se que as pessoas respirem os gases e vapores exauridos pela bomba de vácuo.

Um fator que precisa ser considerado é a quantidade de captura realizada. Durante um dia de trabalho, o número de captura foi de apenas um. Dessa forma, não se colocou em risco o funcionamento da bomba mecânica de palhetas. Para fazer uma quantidade maior de coleta de vapores do tanque de despejo é necessário ter várias unidades de armadilhas geladas.

Outro aspecto fundamental nesse trabalho é o desenho básico da armadilha gelada (Fig. 6). Sua estrutura é constituída de aço



Figura 6: A armadilha gelada usada no trabalho é mostrada dentro de um container amarelo posicionado ao lado da bomba mecânica de palhetas. 
inoxidável, e seu interior possui palha de aço para aumentar a área necessária para aprisionar o vapor a ser analisado. Durante o funcionamento, seu lado exterior fica em contato com $\mathrm{CO}_{2}$ sólido. Certamente, a eficiência da armadilha gelada necessita de um cálculo de transferência de calor, construir aletas internas e utilizar materiais absorvedores e bons condutores de calor. No caso do arranjo experimental considerado neste trabalho, a armadilha gelada foi disponibilizada pelo Laboratório de Tecnologia do Vácuo (LTV) da Fatec São Paulo, e se mostrou suficiente para os propósitos deste estudo.

\section{Operação do sistema de vácuo}

No início da operação, as válvulas (3) e (4) devem estar fechadas e a válvula (6) aberta. A válvula (2) não foi instalada para a operação. Em seguida, o bombeamento de parte da linha é realizado a partir da válvula (3). A armadilha gelada também é bombeada e deve estar em temperatura ambiente até o momento. O resfriamento da armadilha gelada tem início quando a pressão alcançar aproximadamente $2 \times 10^{-1} \mathrm{mbar}$, ficando sob refrigeração por aproximadamente $30 \mathrm{~min}$.

Ao iniciar o despejo do líquido e subsequente formação de vapores, a válvula (3) é aberta. É realizado o bombeamento de gases da atmosfera e dos vapores do líquido despejado. Ao verificar pouco vapor produzido, as válvulas (3) e (4) são fechadas, finalizando o resfriamento da armadilha gelada.

A armadilha gelada deve ser removida do circuito de vácuo com as válvulas (3) e (4) fechadas e a bomba de vácuo desligada. Podese conectar outra armadilha gelada para uma nova amostragem de vapores, se for o caso. É fortemente recomendado que a bomba de vácuo seja novamente ligada a fim de bombear os vapores que ainda estejam na tubulação da linha de bombeamento e em seus componentes.

Deve-se certamente prestar atenção nas questões referentes à manutenção dos elementos que compõem o sistema de vácuo, principalmente da bomba mecânica de palhetas. Ela não é uma bomba de vácuo adequada ao bombeamento de vapores devido ao seu princípio de funcionamento. Mesmo com a armadilha gelada e o filtro instalado na entrada da bomba de vácuo, é recorrente a entrada de vapores na bomba de vácuo e, graças a isso, especial atenção deve ser dada ao aspecto do óleo da bomba de vácuo.

\section{Procedimentos para análise dos vapores orgânicos aprisionados}

O propósito da coleta dos vapores é a sua identificação, usando métodos analíticos disponíveis e confiáveis. Neste trabalho, foi escolhido o método do analisador de gases residuais (RGA, do inglês residual gas analyzer). Este equipamento analítico é utilizado em áreas da pesquisa e da produção em que processos ocorrem com o emprego de sistemas de alto vácuo. O RGA pode ser considerado um espectrômetro de massa e, para o seu funcionamento, há a necessidade de operar pressões menores que $5 \times 10^{-4}$ mbar.

A Fig. 7 mostra um sistema de alto vácuo com o RGA acoplado e a armadilha gelada com vapores retidos em seu interior. Durante a fase de retenção dos vapores, a armadilha estava à baixa temperatura. Depois, a armadilha fica à temperatura ambiente $\mathrm{e}$ assim permanece durante sua instalação no sistema de alto vácuo com o RGA.

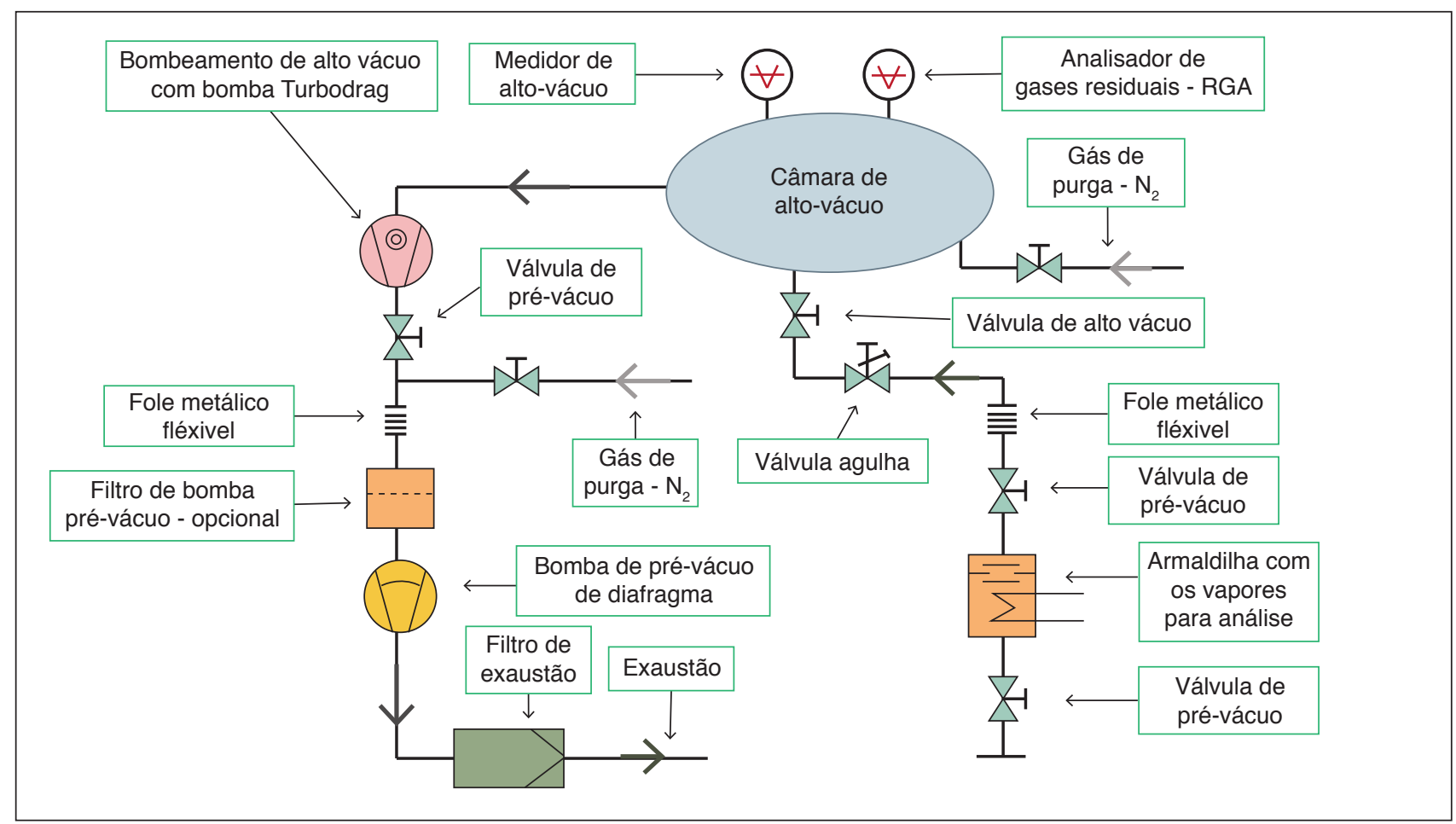

Figura 7: Sistema de alto vácuo com o analisador de gases residuais e a armadilha de vapores acoplados. 
A dosagem controlada da amostra a partir da armadilha até o sistema de alto vácuo, com o RGA ligado, é realizada por meio da válvula-agulha. Para isso, a pressão na câmara de alto vácuo não pode ser superior a $5 \times 10^{-4}$ mbar.

\section{CONCLUSÕES}

Foi apresentado detalhadamente o descritivo do sistema de vácuo para coleta dos vapores, em particular da armadilha gelada, mostrando que foi possível sua construção de forma simples e econômica com o propósito de coletar vapores de uma autoclave, no local de operação do sistema de tratamento de RSS, para posterior análise e identificação dos componentes do vapor gerado.

Foram apresentados também os cálculos das grandezas fundamentais do transporte dos vapores e gases bombeados pela bomba de vácuo mecânica de palhetas.

Ao projetar uma armadilha gelada, deve-se tomar cuidado no uso de materiais que são bons condutores de calor. A limpeza do sistema de vácuo e, em particular, da armadilha gelada é fundamental, pois com isso procura-se garantir a credibilidade na detecção dos vapores coletados. Cada coleta de vapores é única, com dependência na forma como a descarga do líquido e vapor de resíduos são lançados da autoclave.

A técnica de posicionamento do tubo da linha de bombeamento para o transporte dos vapores para obter uma coleta rica em vapores deverá ser aprendida na prática. Recomenda-se que algumas unidades de armadilha gelada sejam construídas para coletar uma quantidade suficiente de amostras de vapores que assegure conclusões seguras e confiáveis.

\section{AGRADECIMENTOS}

Ao Laboratório de Tecnologia de Vácuo da Faculdade de Tecnologia de São Paulo, pelo empréstimo das bombas e montagem do arranjo experimental.

\section{REFERÊNCIAS}

1. Turiel I, Hollowell CD, Miksch RR, Rudy JV, Young RA, Coye MJ. The effects of reduced ventilation on indoor air quality in an office building. Atmos Environ. 1983;17(1):51-64. https://doi. org/10.1016/0004-6981(83)90007-0
2. Brickus LSR, Aquino Neto FR. Indoor Air Quality and Chemistry. Quím Nova. 1999;22(1):65-74. https://doi.org/10.1590/S010040421999000100013

3. Lee $\mathrm{H}$, Awbi HB. Effect of internal partitioning on indoor air quality of rooms with mixing ventilation: basic study. Build Env. 2004;39(2):27-41. https://doi.org/10.1016/j.buildenv.2003.08.007

4. Piceli PC, Lisboa HM. Quantificação de benzeno, tolueno, etilbenzeno e xilenos no ar de ambientes internos. Eng Sanit Ambient. 2018;23(3):527-34. https://doi.org/10.1590/s141341522018119310

5. Piceli PC. Quantificação de benzeno, tolueno, etilbenzeno e xileno no ar de ambientes ocupacionais [Dissertação de Mestrado]. Santa Catarina (SC): Universidade Federal de Santa Catarina; 2005.

6. World Health Organization. Indoor air pollutants: exposure and health effects. Copenhagen: WHO; 1989

7. JonesAP. Indoor air quality and health. Atmos Environ. 1999;33(28):453564. https://doi.org/10.1016/S1352-2310(99)00272-1

8. Gioda A, Aquino Neto FR. Poluição química relacionada ao ar de interiores no Brasil. Quím Nova. 2003;26(3):356-65. https://doi. org/10.1590/S0100-40422003000300013

9. Nunes TF. Emissões biogênicas de hidrocarbonetos não metano: contribuição para a determinação das taxas de emissão de compostos orgânicos voláteis (COVs) pelos ecossistemas florestais [Tese de Doutorado]. Portugal (PT): Universidade de Aveiro; 1996

10. Ministério da Saúde (Brasil); Agência Nacional de Vigilância Sanitária (Anvisa). Dispõe sobre a simplificação de procedimentos para a importação de bens e produtos sujeitos à Vigilância Sanitária. Resolução da Diretoria Colegiada-RDC N 208, de 5 de janeiro de 2018. [Acesso: 15 out 2018]. Disponível em: http://portal. anvisa.gov.br/documents/10181/2957335/RDC_208_2018_.pdf/ eccf9152-9aae-43d0-83b4-e2f6b3015425

11. Belli Filho P, Lisboa HM. Avaliação de emissões odorantes. Eng Sanit Ambient. 1998;3(3-4):101-106.

12. Brandeburgo PA. Avaliação da Percepção de Odores por Colaboradores de uma Indústria de Papel e Celulose [Trabalho de Conclusão de Curso]. Santa Catarina (SC): Engenharia Sanitária e Ambiental. Universidade Federal de Santa Catarina; 2011.

13. Buschinelli JT, Kato M. Manual para interpretação de informações sobre substâncias químicas. São Paulo: Fundacentro; 2011.

14. CARMO JR, GNR. Otimização e avaliação de metodologias olfatométricas voltadas ao saneamento ambiental. Programa de Pós-graduação em Engenharia Ambiental. Universidade Federal de Santa Catarina. Tese de doutorado, 2005, 186 p.

15. LEYBOLD. Full Line Catalog. Bombas de Vácuo Trivac E. [Acesso: 23 jul 2019]. Disponível em: https://www.leybold.com/ epaper/en/\#2 